\title{
Relating Fire Occurrence to Weather Condi- tions on the Great Basin Rangelands
}

\author{
KENNETH G. HUBBARD
}

\begin{abstract}
Results are presented to demonstrate the association between weather conditions and fire danger on the rangelands of the Great Basin. It was found that precipitation frequency and duration are physically related to fire occurrence in a complex manner. A climatic relationship also exists between monthly temperature and the corresponding total number of fires for a specific area.
\end{abstract}

On sparsely inhabited Bureau of Land Management (BLM) rangelands in the Great Basin, fire weather stations are separated by great distances. Consequently, large areas of land are unobserved. Furthermore, there is the question of whether individual station location and exposure are representative of fire problem areas. Current observations of fire weather and danger are made in conjunction with the National Fire Danger Rating System (NFDRS). This system was developed by the National Forest Service Personnel and has been described in detail (Deeming et al. 1978). Other references concerning fire weather (Schroeder et al. 1970) and wildfire behavior (Albini 1976) are also available to relate the impact of weather on fires and fire danger.

Use of the NFDRS by fire management personnel involves the input of weather data on a daily basis as a requirement for predicting an index or component of fire danger. The principal parameters which are output to field personnel are described in Table 1. Instructions concerning actual applications of these predictions are given in Deeming et al. (1978) in which the stated purpose of the system is to evaluate "the near upper limit of the behavior of fires that might occur on a rating area during the rating period'.

The purpose of the study was to examine the NFDRS indices and components with respect to actual fire occurrence and behavior in the Great Basin area, to examine other weather data in regard to fire conditions, and to indicate zones within which the fire occurrence and behavior would be homogeneous in response to existing climate characteristics. In this paper findings with regard to the first two objectives listed above are discussed.

\section{Methodology}

Fire occurrence on the rangelands of the Great Basin was examined in the light of weather data presently a vailable for the purpose of determining efficiency of the existing fire

\footnotetext{
The author is climatologist, Utah Department of Agriculture, Utah State University, UMC 48 Logan, Utah 84322.

This study was supported by the Bureau of Land Management (BLM) through contract YA-512-C77-198. In addition, the contribution of data from various government agencies including the BLM and the U.S. Forest Service is acknowledged. Manuscript received March 26, 1979.
}

weather network. Fire weather station data (Fisher et al. 1972) was obtained from the National Fire Weather Library (Furman et al. 1975). National Weather Service stations were used to supplement data from the fire weather stations. The average impact of climate, as well as the day to day influence of weather on fire occurrence, was studied. Fire reports were examined to determinc the location and occurrence of individual fires.

\section{Results and Discussion}

Fire frequency data from individual BLM districts showed that the fire season was generally May through October (e.g., Fig. la and Ib). The highest frequency of fires was usually in July for the Great Basin Fire Districts examined. In a few districts August was the month of highest fire frequency which probably reflects a different vegetative regime.

\section{Seasonal Relationship}

Examination of temperature data showed that a seasonal relationship exists between fire occurrence and average

Table 1. Fire danger indices and components which are calculated using the National Fire Danger Rating System (NFDRS).

\section{Fire Behavior Potential}

Spread Component (SC) - the forward rate of fire spread.

Engergy Release Component (ERC)-the potential available energy released per unit area in the fires flames.

Fire Occurrence

Ignition Component (IC)—related to the probability that a fire would result if a fire brand (lightning, spark, etc.) were introduced.

Lightning Risk (LR) - a combination of thunderstorm prediction or observation and a local factor derived from records of lightning activity.

Man-Caused Risk (MCR) - a rating assigned by the fire manager to reflect the activities of man in the area of concern.

Fire Control Planning

Lightning Occurrence Index (LOI)-a combination of LR and IC (see above).

Man-Caused Occurrence Index (MCOI)-a combination of MCR and IC (see above).

Burn Index $(\mathrm{BI})$ - related to the difficulty of fire containment (from $\mathrm{SC}$ and ERC above).

Fire Load Index (FLI)-combination of fire occurrence and behavior into a single number. 


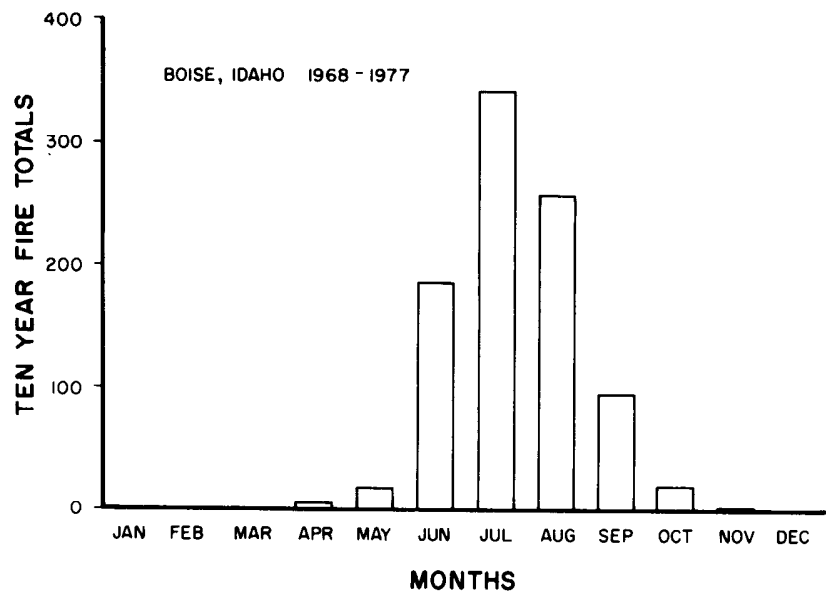

Fig. 1a. Ten-year fire totals for the Boise fire district of southern Idaho, shown as individual monthly totals.

temperature (Fig. 2). Differences in plant communitics, seasonal precipitation, and lightning frequency may modify the curve for a given district. As new lightning detection systems (Vance et al. 1978) begin to operate, and plant communities in relation to their fire potential are identified, the seasonal relationships may be refined. As can be seen by examining the average fire count associated with a temperature of $60^{\circ} \mathrm{F}$, the differences in fire occurrence from district to district is quite large. Reading the intersection of the $60^{\circ}$ $F$ temperature with the Las Vegas, Salt Lake, and Boise curves results in fire total of 5,20 , and 250 respectively in a ten year period. On the average, a temperature of $60^{\circ} \mathrm{F}$ is attained in early Arpil in the Las Vegas District. The Salt Lake District warms to $60^{\circ}$ in mid June while the major portion of the Boise District does not attain $60^{\circ}$ until in July. Thus, a specific temperature does not fall in the same frame relative to the fire season. With respect to the vegeta-

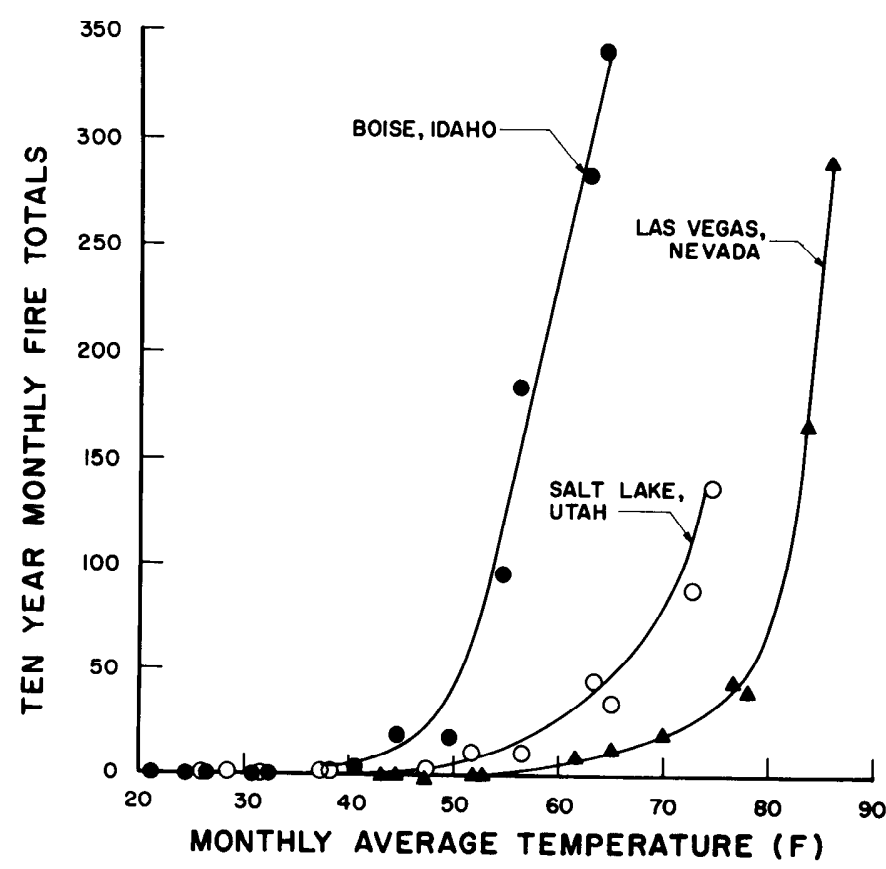

Fig. 2. The climatic relationship between temperature and fire occurrence on the fire districts indicated. Average monthly temperature was determined from 30-year normals in appropriate climatic divisions by a weighting technique. The curves were fitted by sight.

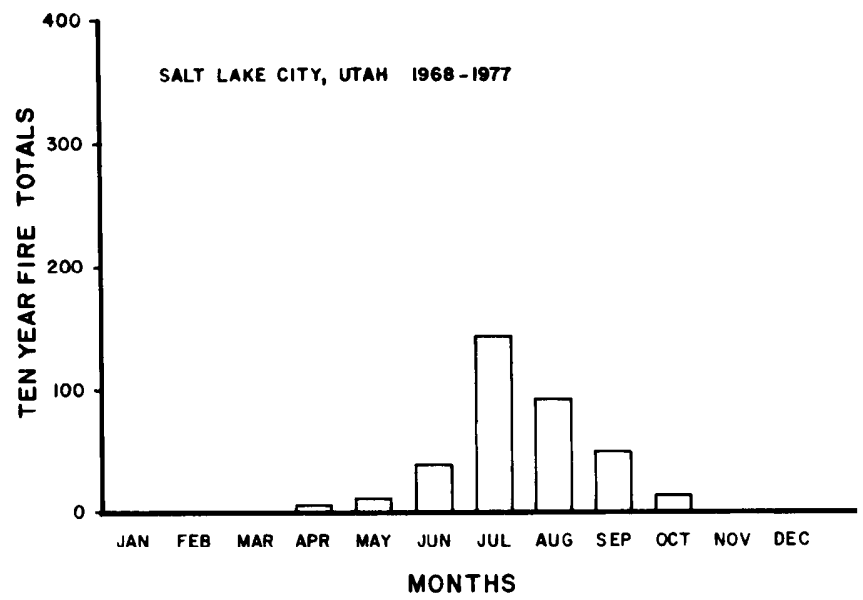

Fig. 1b. Ten-year fire totals for the Salt Lake fire district of western Utah. shown as individual monthly totals.

tion characteristics of various districts, a specific temperature would occur at different stages of development, early for some and late for others. Climate, as it affects plant growth, underlines the physical mechanisms linking fire ignition to weather parameters.

\section{Precipitation}

Storms which occur during the fire season are usually of a convective nature, which result in thunderclouds. An increase in lightning risk quite often accompanies any precipitation received at the surface. An examination was made of the fire activity and the precipitation occurrence to ascertain what significance could be attached to the increased lightning activity. The results indicated that the beginning of a precipitation episode is often accompanied by an increase in the number of fires reported.

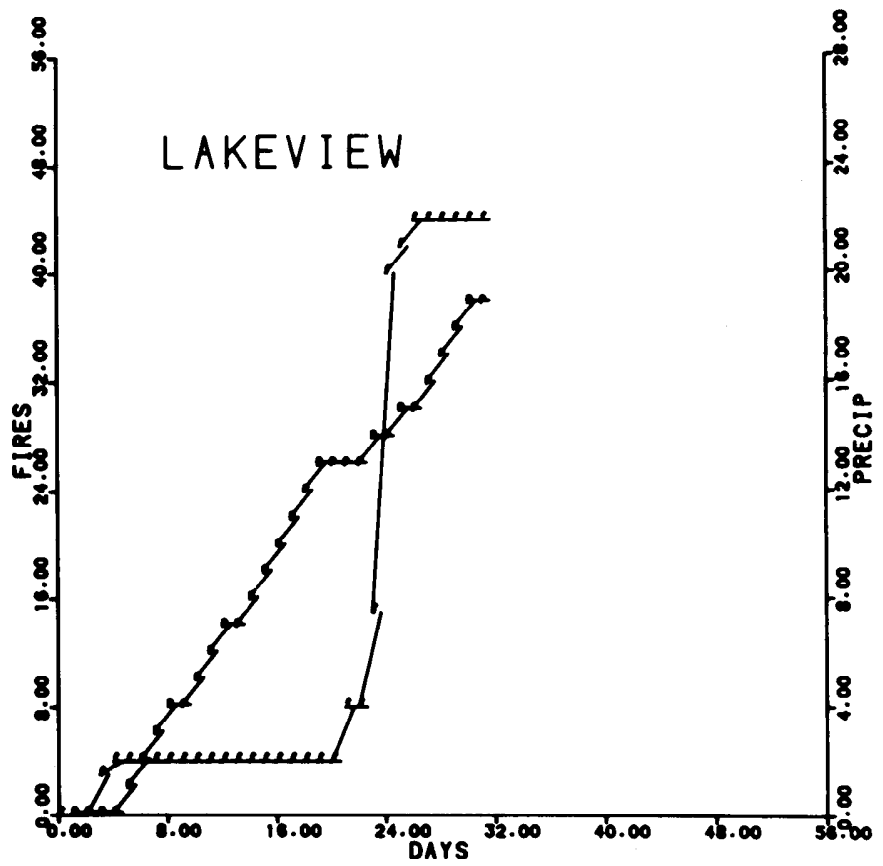

Fig. 3. Accumulated fire occurrence and the accumulated number of days with precipitation for the Lakeview fire district of southern Oregon. The $\mathrm{x}$-axis shows the day number beginning with June 1, 1970 and the $\mathrm{y}$-axis gives the fire count. Along the right hand side is an axis labeled "PRECIP," which corresponds to the curve labeled $\mathrm{p}$ for the precipitation occurrence. 
A typical case of coincident fire and precipitation activity is shown in Figure 3. During June, there were 19 days with precipitation reported. The accumulation of the number of days with precipitation at the Hart Mountain Weather Station shows that fires increase with the initial precipitation on the third day. No fires are reported from the fourth day through day number 20 . During this same time period, precipitation occurrence is characterized by a marked increase in precipitation days until day 16 , when the area enters a period of several dry days. When precipitation begins again on the 21 st of June, the number of fires increases dramatically. A similar relationship between days with precipitation and fire occurrence exists for many of the districts studied.

Fire occurrence increases in the beginning of a precipitation event and decreases as the number of continuous precipitation days increase. The highest increase in fire occurrence was usually associated with shorter duration episodes, presumably due to the high percentage of lightning associated thunderstorms occurring as one day events and the greater wetting capacity of longer events. Long duration precipitation episodes would be the result of either 1) a relatively moist air mass and large scale lifting with general precipitation or 2) a string of thunderstorm events caused by surface heating. The type of precipitation (thunderstorms or otherwise) impending on any day would be easier to specify than forecasting actual amounts.

\section{National Fire Danger Rating System}

The 1978 NFDRS calculates fire danger indices and components for daily inputs of weather measurements (Deeming et al. 1978). NFDRS outputs are defined in Table 1. These model outputs have been described as linear estimates of the relative danger for each of the corresponding fire characteristics being rated. Daily fire danger indices and components were calculated for each Nevada fire weather station in the State of Nevada during the 1975 and 1976 fire seasons. The Lightning Occurrence Index (LOI) was compared to actual fire occurrence as determined for fire reports. The relationship between LOI and fires reported did not warrant an examination of the linear correlation between the two on a daily basis in any of the districts studied due to the fact that the time traces were not in phase.

It was further determined that the impact of inputting precipitation into the NFDRS was to greatly reduce the values of all indices and components calculated. Because summer convection often results in spotty precipitation at the surface, it follows that indices at a fire weather station are quite limited in their ability to represent the fire danger in surrounding areas.

\section{Conclusions}

The occurrence and the duration of precipitation episodes were two important factors in determining the climatology of fire weather in the Great Basin. It was concluded that a reliable forecast of the type and/or duration of precipitation would be helpful in estimating the number of fires that occur over a given time interval. Better use of the NFDRS rating could be realized by accounting for the areal distribution of precipitation. It was further concluded that keeping several sets of fire danger indices at a fire weather station to account for the wide range of conditions inherent in arid climate with convective storms would improve the representation of fire danger predictions. Determining precipitation distribution may offer a possible solution to the problem caused by variable stormtrack and intensity within each fire district.

An examination of the NFDRS indices and components did not give the expected relationship between fire occurrence and LOI. It was found for the Great Basin that precipitation, when input to the NFDRS, caused significant reductions of all indices and components in contrast to the increase in the number of fires observed. When lightning detection networks become operational over rangelands, the resulting historical lightning data could improve the relationships.

Of the meteorological factors studied, frequency of days with precipitation was found to have the most significant relationship to daily fire occurrence and could no doubt improve the present fire occurrence indicators.

\section{Literature Cited}

Albini, F.A. 1976. Estimating wildfire behavior and effects. U.S. Dep. Agr. Forest Serv. Gen. Tech. Rep. INT-30. 92 p.

Deeming, J.E., R.E. Burgan, and J.D. Cohen. 1978. The National Fire Danger Rating System-1978. Gen. Tech. Rep. INT-39. 117 p.

Fischer, W.C., and C.E. Hardy. 1972. Fire-weather observers handbook. U.S. Dep. Agr. Forest Serv. 152 p.

Furman, R.W., and G.E. Brink. 1975. The National Fire Weather Data Library: What it is and How to Use it. U.S. Dep. Agr. Forest Serv. Gen. Tech. Rep. R17-19. 8 p.

Schroeder, M.J, and C.C. Burk. 1970. Fire Weather. U.S. Dep. Agr. Forest Serv. Handbk 360. 229 p.

Vance, D.L., and E.P. Krider. 1978. Lightning detecting systems for fire management. Fifth Conference on Fire and Forest Meteorology. Atlantic City, NJ. March 14-17, 1978 